\title{
Wetting in infiltration of alumina particle preforms with molten copper
}

\author{
M. BAHRAINI, L. WEBER \\ Laboratory of Mechanical Metallurgy, Institute of Materials, Swiss Federal Institute of \\ Technology in Lausanne (EPFL), EPFL, CH-1015, Lausanne, Switzerland
}

J. NARCISO

Department of Inorganic Chemistry, University of Alicante, Spain

\author{
A. MORTENSEN \\ Laboratory of Mechanical Metallurgy, Institute of Materials, Swiss Federal Institute of \\ Technology in Lausanne (EPFL), EPFL, CH-1015, Lausanne, Switzerland
}

\begin{abstract}
The high-temperature wettability of alumina particulate preforms by copper is investigated by means of infiltration experiments conducted at $1473 \mathrm{~K}$ under low oxygen partial pressure. Wetting is quantified in terms of drainage curves, which plot the volume fraction of metal in the porous medium vs. the applied pressure. Mercury porosimetry is also used on similar preforms for comparison. The effect of volume fraction, particle geometry and capillary parameters on the drainage curve are studied and compared with the expression proposed by Brooks and Corey. The influence of the particle volume fraction and capillary parameters characterizing wetting in the two systems is discussed to derive an effective contact angle for wetting of alumina particles by molten copper.

(c) 2005 Springer Science + Business Media, Inc.
\end{abstract}

\section{Introduction}

Liquid metal infiltration is one of the principal processes used for the fabrication of ceramic fiber or particle reinforced composites with matrices based on lower melting point metals such as $\mathrm{Al}$ or $\mathrm{Cu}$. A parameter of primary importance in this process is the degree of wetting of the ceramic reinforcement by the metal: if capillary forces oppose infiltration, pressure must be applied on the metal before it will flow into open pores of the ceramic preform $[1,2]$.

Basic capillary parameters characterizing infiltration are those that describe the work of immersion of the ceramic in the metal, expressible using Young's equation [1-9] as:

$$
W_{\mathrm{i}} \equiv \sigma_{\mathrm{ls}}-\sigma_{\mathrm{sv}}=-\sigma_{\mathrm{lv}} \cos (\theta)
$$

where $\sigma_{\mathrm{ls}}, \sigma_{\mathrm{sv}}$ and $\sigma_{\mathrm{lv}}$ are, respectively, the liquid/solid, solid/vapour and liquid/vapour interfacial energies, and $\theta$ is the contact angle measured through the liquid. Since $\sigma_{\mathrm{lv}}$ and $\theta$ can be measured using the sessile drop experiment [6], $W_{\mathrm{i}}$ is accessible to experiment. Under some conditions, namely when slug-flow (plane-front) infiltration is observed, $W_{\mathrm{i}}$ can be correlated directly with the capillary pressure drop $\Delta P_{\gamma}$ that must be overcome to drive infiltration $[1,2,4,5,10]$ :

$$
\begin{aligned}
\Delta P_{\gamma} & =V_{\mathrm{r}}\left(1-V_{\mathrm{r}}\right)^{-1} A_{\mathrm{v}}\left(\sigma_{\mathrm{ls}}-\sigma_{\mathrm{sv}}\right) \\
& =-V_{\mathrm{r}}\left(1-V_{\mathrm{r}}\right)^{-1} A_{\mathrm{v}} \sigma_{\mathrm{lv}} \cos (\theta)
\end{aligned}
$$

where $V_{\mathrm{r}}$ is the volume fraction reinforcement in the preform, and $A_{\mathrm{v}}$ is the reinforcement surface area per unit volume of the reinforcement.

This approach is unfortunately not always sufficient: it often provides an insufficient characterization of capillarity in infiltration processing, for two reasons. The first is that intrinsic capillary parameters $\left(\sigma_{\mathrm{ls}}, \sigma_{\mathrm{sv}}, \sigma_{\mathrm{lv}}\right.$ and $\theta$ ) characteristic of dynamic wetting of a discrete reinforcement may sometimes not be the same as those measured under in the near-static conditions characteristic of sessile drop experiments. A second reason is that fluids generally invade preforms over a range of pressures that are largely governed by the complex internal geometry of open pores within the ceramic preform [13]. A single scalar is, then, insufficient to characterize wetting during infiltration.

This problem is encountered in several branches of engineering science, including for example reservoir engineering or soil science. Characterization of wetting during infiltration is then conducted by measuring drainage curves, which are plots of the volume fraction of non-wetting fluid in the porous medium versus the pressure difference $P$ between the fluid and the atmosphere in the pores $[1-3,11]$.

Drainage curves relevant to aluminium infiltrating short-fiber preforms have been measured and have been used with success to model infiltration processing of alumina short fiber reinforced aluminium [12-14]. We extend here this approach towards the characterization of wetting by molten copper of fine alumina particle preforms. We show that the data agree with the simple 
formula of Brooks and Corey, as do drainage curves measured on the same preforms by mercury porosimetry. We also show that the two sets of data, for $\mathrm{Hg}$ and $\mathrm{Cu}$, agree with one another after simple transformation by a multiplicative constant that reflects differences in relevant capillary parameters. The implications are twofold: (i) mercury porosimetry may provide a convenient method of accessing relevant geometrical characteristics to quantify wetting of a given preform by other metals, and (ii) comparison between mercury porosimetry data and drainage curves may provide a method for the measurement of intrinsic capillary parameters that are directly relevant to infiltration processing.

\section{Experimental procedure}

\subsection{Materials and infiltration processing}

Alumina angular and polygonal particulates ( $\alpha$ $\mathrm{Al}_{2} \mathrm{O}_{3}$ F1000 purchased from Treibacher Schleifmittel (Laufenburg, Germany) and Sumicorundum AA-5, provided by Sumitomo (Osaka, Japan)), both of average diameter near $5 \mu \mathrm{m}$, were used for preparing the preforms. ETP $\mathrm{Cu}$ was used as the molten infiltrating matrix.

Preforms from angular powder were prepared by two different routes: (i) by tapping and vibrating the powder directly into its crucible, and (ii) by cold isostatically pressing (CIP) at $150 \mathrm{MPa}$. The two methods yield volume fractions alumina of 0.46 and 0.54 , respectively. The volume fraction of the preform based on polygonal powder pressed by CIP at the same pressure is 0.63 . The obtained preforms were cylindrical, about $10 \mathrm{~mm}$ in diameter and $15 \mathrm{~mm}$ in height.

Drainage experiments were run in a gas-driven pressure infiltration apparatus. The alumina preform and the copper were placed in that order into an alumina crucible. The inner surface of the crucible was coated with graphite to avoid sticking of the final sample to the crucible. Primary vacuum was pulled and followed by purging with argon back to ambient pressure. After having reached again a primary vacuum, the system was heated to $1200^{\circ} \mathrm{C}$ at a rate of $200^{\circ} \mathrm{C} / \mathrm{h}$ by means of an induction coil coupled to a graphite susceptor and subsequently pressurized with Ar gas. Pressure and temperature were maintained for 30 minutes and the system was finally cooled under pressure. Measuring a drainage curve for a given type of preform entailed carrying out a series of infiltrations in this fashion at different applied pressures.
Given the significant influence of the oxygen partial pressure on the surface tension of liquid $\mathrm{Cu}$ [6] and on its reactivity with alumina $[15,16]$, the oxygen partial pressure in the apparatus was measured during the drainage experiments using an oxygen gas analyzer, Rapidox model RX2000 from Cambridge Sensotec Ltd.

\subsection{Microstructural characterization}

The microstructure of the composites was examined for homogeneity and absence of agglomeration of particles. For this purpose samples were sectioned, polished for metallographic examination and observed under an optical microscope, (Zeiss Axioplan universal, Oberkocher, Germany).

\subsection{Measurement of the drainage curves}

The drainage curves of infiltrated samples were obtained by determining the metal volume fraction in the infiltrated composites by means of densitometry based on Archimedes' principle using a Sartorius MC 210P microbalance and Sartorius Gravity Determination kit YDK 0.1 (IG Instrument-Gesellschaft, Zürich, Switzerland). When porosity was present in the sample, wax was used to seal all open pores along its outer surface before immersion in water, the wax surface being carefully leveled with the sample's outer surface beforehand. The apparent density of the partially infiltrated perform was then determined by dividing the weight of the sample without wax by the volume displaced when submerged in the water.

Drainage curves for the same alumina preforms were also measured for infiltration by mercury at room temperature using standard mercury porosimetry experiments, conducted using a Macropores unit 120 and porosimeter $2000 \mathrm{WS}$, CARLO ERBA Instruments. In mercury porosimetry, mercury is gradually infiltrated into the evacuated sample cell $[17,18]$.

\section{Results}

Micrographs of alumina preforms infiltrated by $\mathrm{Cu}$ are given in Figs 1 and 2. It is seen that copper gradually fills the pores in the preform as the applied pressure is increased. The pressure at which the preforms appear fully infiltrated in optical metallography and within the precision of densitometric measurements is around $5 \mathrm{MPa}$ for the polygonal powder and $10 \mathrm{MPa}$ for the

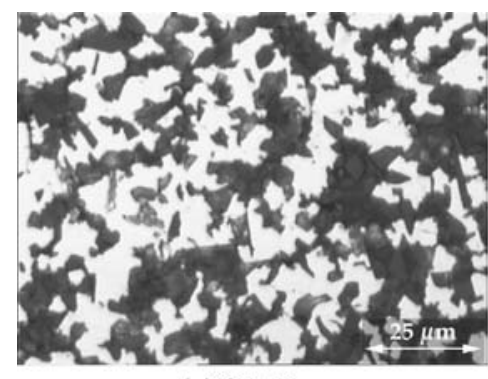

(a) $2 \mathrm{MPa}$

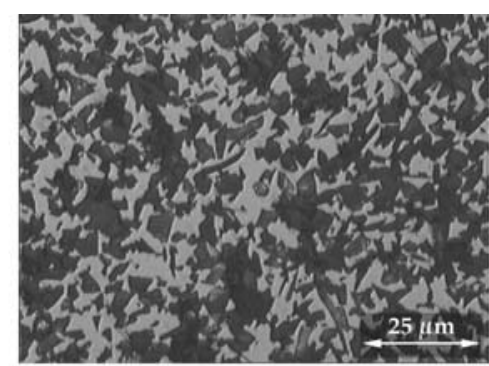

(b) $3.5 \mathrm{MPa}$

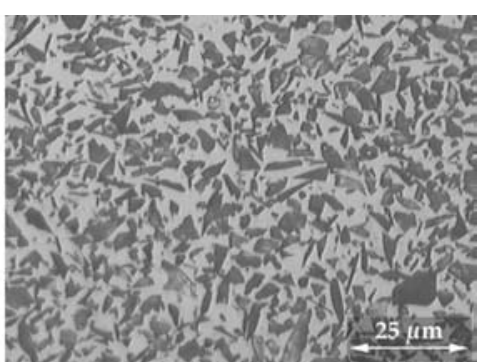

(c) $10 \mathrm{MPa}$

Figure 1 Microstructures of $\mathrm{Cu} /$ alumina composites, angular powder at volume fraction of $0.46\left(T=1200^{\circ} \mathrm{C}\right)$. 


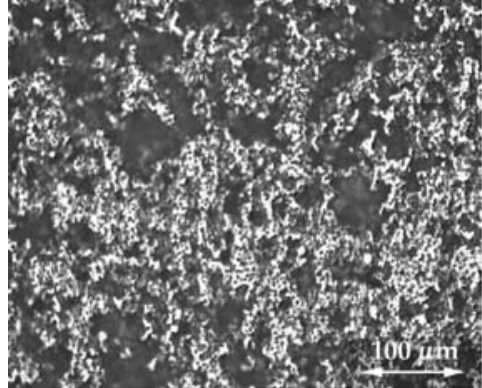

(a) $2.2 \mathrm{MPa}$

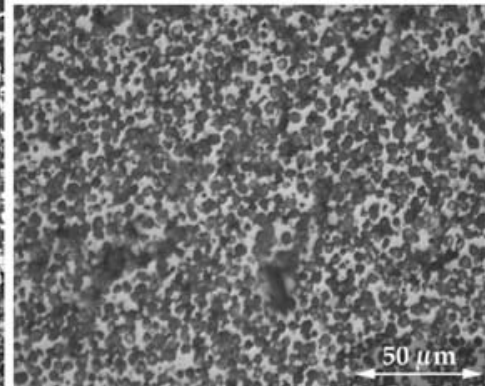

(b) $2.7 \mathrm{MPa}$

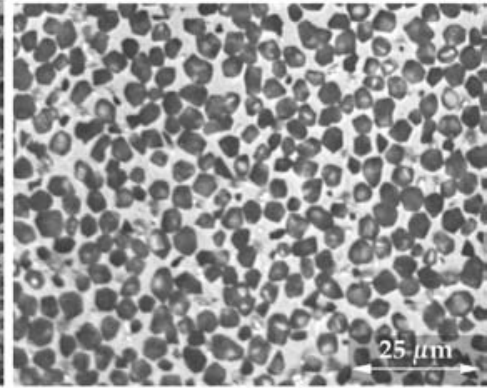

(c) $5 \mathrm{MPa}$

Figure 2 Microstructures of $\mathrm{Cu} /$ alumina composites, polygonal powder at volume fraction of $0.63\left(T=1200^{\circ} \mathrm{C}\right)$.

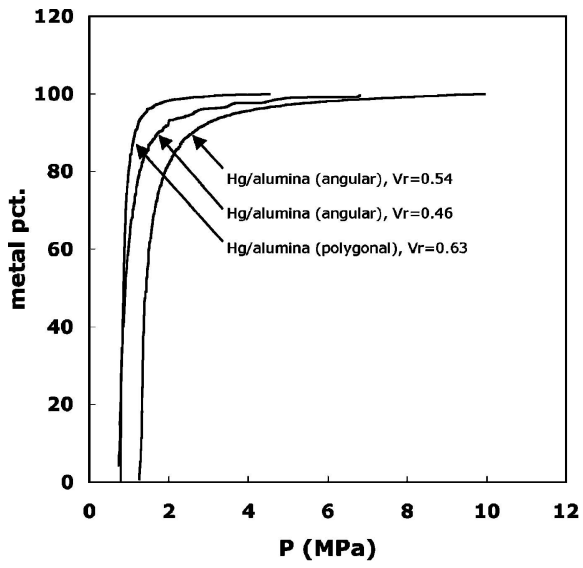

(a)

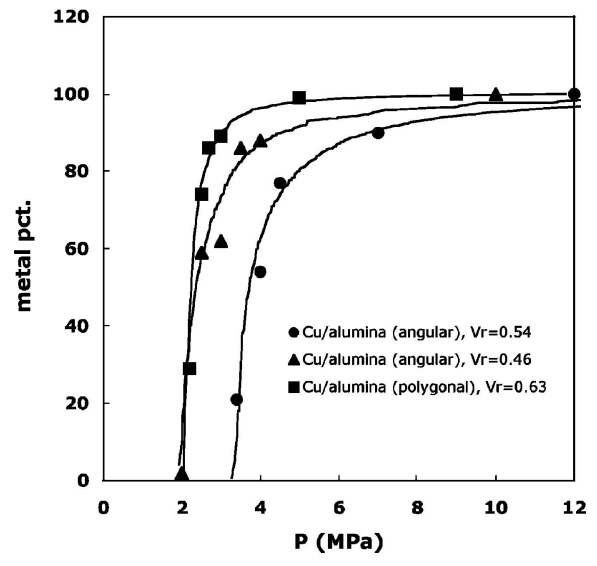

(b)

Figure 3 Drainage curves of (a) $\mathrm{Hg}$ /alumina measured by mercury porosimetry (room temperature) and (b) $\mathrm{Cu} / \mathrm{alumina}$ by densitometry $(T=$ $\left.1200^{\circ} \mathrm{C}\right)$.

angular powder. The drainage curves of the $\mathrm{Hg}$ /alumina and $\mathrm{Cu}$ /alumina systems are given in Fig. $3 \mathrm{a}$ and $\mathrm{b}$.

\section{Discussion}

The oxygen partial pressure measured in the infiltration apparatus was found to decrease with increasing temperature, reaching a very low level at $1200^{\circ} \mathrm{C}$ (less than the detection limit of the apparatus, of $5 \times 10^{-23}$ atmospheres). This can be rationalized by equilibration of residual oxygen in the chamber with the heated graphite susceptor.

The microstructures of the fully infiltrated composites in Figs 1c and 2c are typical for this class of composites. Interfaces are free of visible reaction products, as expected: given the low oxygen chemical activity during infiltration, $\mathrm{Al}_{2} \mathrm{O}_{3}$ is stable in $\mathrm{Cu}[15,16]$.

In partly infiltrated samples, the metal distribution is highly inhomogeneous, Figs 1 and 2 . This is characteristic of drainage, i.e., the invasion of highly percolating pore network by a non-wetting fluid $[19,20]$. On a more macroscopic level, however, the microstructures were relatively uniform, typical microstructures in Figs 1 and 2 being replicated throughout the specimens. The use of densitometry for measurement of the drainage curves is thus legitimate.

A quantitative description of drainage is provided by the Brooks and Corey semi-empirical model [21], previously found to agree with drainage data for the infiltration of alumina short fiber performs by aluminum [13]. According to this model, during infiltration the effective saturation, $S_{\text {eff }}$, can be described as a func- tion of the pressure difference between the infiltrating fluid and the surrounding atmosphere, $P$, by means of a simple two-parameter equation:

$$
S_{\mathrm{eff}}=\frac{V_{\mathrm{P}}}{1-V_{\mathrm{r}}}=\left(\frac{P_{\mathrm{b}}}{P}\right)^{\lambda}
$$

where the effective saturation $S_{\text {eff }}$ is defined as the ratio between the volume fraction occupied by the wetting fluid (the atmosphere in the present case: $V_{\mathrm{P}}=1-$ $V_{\mathrm{m}}$ where $V_{\mathrm{m}}$ is the volume fraction metal), and the total initial interconnected pore volume fraction $\left(1-V_{\mathrm{r}}\right)$ where $V_{\mathrm{r}}$ is the reinforcement volume fraction. This definition is used here because full infiltration is indeed achieved at high pressures, Figs 1c and 2c; hence the "residual saturation" of wetting fluid is nil in the present systems [11].

In this expression, two characteristic parameters describe the porous medium/infiltrant system at hand: (i) the "pore size distribution index", $\lambda$, and (ii) the "bubbling pressure," $P_{\mathrm{b}}$. The pore size distribution index $\lambda$ is related to the microscopic geometry of the porous medium; it is small for media having a wide range of pore sizes and large for media with a relatively uniform pore size. As worded by Brooks and Corey, the bubbling pressure $P_{\mathrm{b}}$ represents the smallest capillary pressure at which a continuous non-wetting phase exists in the pores of the porous medium (as indeed suggested by Equation 3) [21].

If Equation 3 holds, then plotting $\log \left(S_{\text {eff }}\right)$ versus $\log (P)$ should yield straight lines of slope $(-\lambda)$. Such 


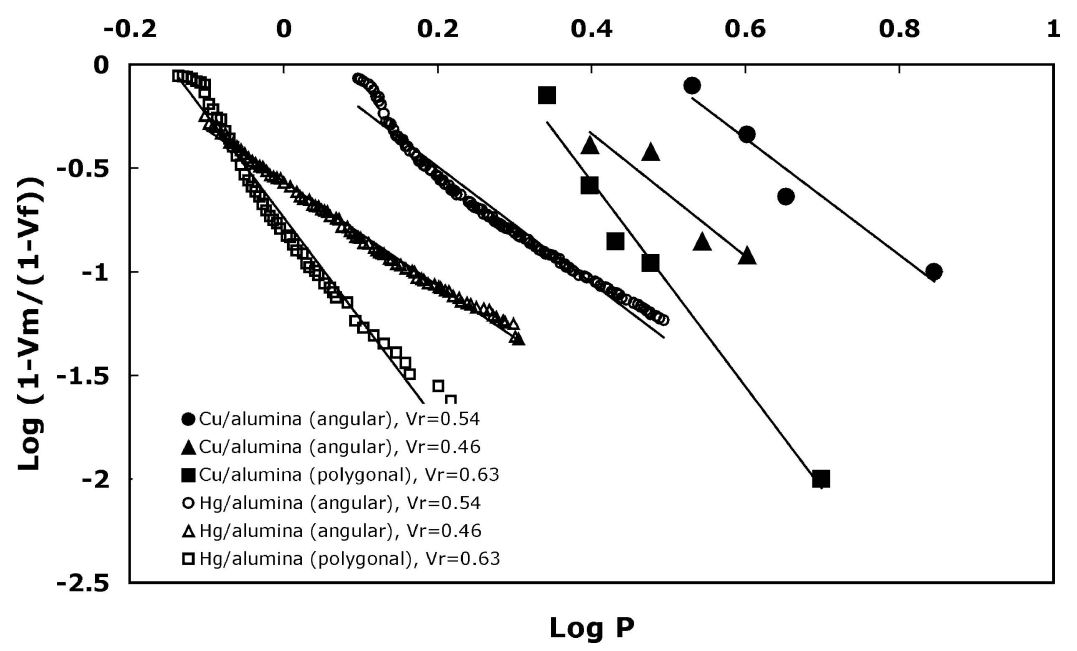

Figure 4 Experimental drainage curves of $\mathrm{Cu} / \mathrm{Al}_{2} \mathrm{O}_{3}$ and $\mathrm{Hg} / \mathrm{Al}_{2} \mathrm{O}_{3}$ compared with Brooks and Corey model.

plots are shown in Fig. 4: as seen, after a small nonlinear portion at low pressure the mercury porosimetry data become roughly linear over the majority of their range. Straight lines are also compatible with the (more scarce and scattered) copper data. The measured slope $(-\lambda)$ of these lines is the same for each of the two particle types, independently of the nature of the infiltrant or the powder packing volume fraction $V_{\mathrm{r}}$. Furthermore, $(-\lambda)$ is higher for the polygonal particles, as expected given their more regular shape and narrower size distribution compared with the angular particles (see Figs 1 and 2). The nature and shape of the solid particles making the preform thus do indeed appear to be embodied in this single scalar, $\lambda$, consistent with the model. In the Brooks-Corey correlation, then, the "bubbling pressure" $P_{\mathrm{b}}$ reflects alone the influence of $V_{\mathrm{r}}$ and of intrinsic capillary parameters (or in other words of the infiltrant nature plus infiltration conditions such as temperature and atmosphere).

More generally, if the shape of drainage curves is determined by the shape of particles making the preform while a single scaling factor for pressure $P_{\mathrm{b}}$ accounts for the influence of capillary parameters and $V_{\mathrm{r}}$, then it is to be expected that, for a given shape of particles in the preform, the capillary pressure $P$ at given saturation be proportional to the capillary pressure drop $\Delta P_{\gamma}$ defined in Equation (2). Constant and predictable horizontal shifts of the curves in Fig. 4 will then result from fixed changes in any of (i) the work of immersion $\sigma_{\mathrm{lv}}$ $\cos (\theta)$, (ii) the particle volume fraction $V_{\mathrm{r}}$ and/or (iii) the particle size (contained in $A_{\mathrm{v}}$, which for a given particle type and surface roughness ratio is proportional to the inverse of the particle diameter).

With angular particles, it is indeed seen that, as $V_{\mathrm{r}}$ is increased from 0.46 to 0.54 , the corresponding lines in Fig. 4 are shifted horizontally by $\Delta \log (\mathrm{P})$ values of 0.22 and 0.20 for the $\mathrm{Hg}$ and $\mathrm{Cu}$ data respectively. This corresponds to a scaling of pressures by a factor of $\approx 1.6$, in acceptable agreement with:

$$
\frac{V_{\mathrm{r}}^{\text {CIPed }}}{V_{\mathrm{r}}^{\text {tapped }}} \cdot \frac{1-V_{\mathrm{r}}^{\text {tapped }}}{1-V_{\mathrm{r}}^{\mathrm{CIPed}}}=\frac{0.54}{0.46} \cdot \frac{0.54}{0.46} \approx 1.4
$$

For a given preform type and volume fraction, changing the infiltrating liquid from mercury to copper should produce a shift in drainage curves by multiplication of pressures with a scaling factor $\varphi$ :

$$
\varphi=\frac{\sigma_{\mathrm{LV}}^{\mathrm{Cu}} \cdot \cos \left(\theta_{\mathrm{Cu} / \mathrm{Al}_{2} \mathrm{O}_{3}}\right)}{\sigma_{\mathrm{LV}}^{\mathrm{Hg}} \cdot \cos \left(\theta_{\mathrm{Hg} / \mathrm{Al}_{2} \mathrm{O}_{3}}\right)}
$$

where $\sigma_{\mathrm{LV}}^{\mathrm{Cu}}, \sigma_{\mathrm{LV}}^{\mathrm{Hg}}, \theta_{\mathrm{Cu} / \mathrm{Al}_{2} \mathrm{O}_{3}}$, and $\theta_{\mathrm{Hg} / \mathrm{Al}_{2} \mathrm{O}_{3}}$ are the surface energies and contact angles with alumina of liquid copper and mercury, respectively. On Fig. 4 this corresponds to a constant horizontal translation of the two sets of three curves, as is indeed observed: the $\mathrm{Cu}$ /alumina and the $\mathrm{Hg}$ /alumina data are shifted by the same $\Delta \log (\mathrm{P})$ value of 0.415 for all three preforms, corresponding to a scaling of the pressure by a factor of 2.6 from mercury porosimetry to copper infiltration. This is also well illustrated directly on the drainage curves, Fig. 3b, where the data points are for $\mathrm{Cu}$ while the lines traced through the data are in fact the measured mercury porosimetry curves after multiplication of $P$ by $\varphi=2.6$.

Values in the literature for the four capillary parameteres in Equation (6) are listed in Table I (values of contact angles of copper in Table I are for very low oxygen partial pressure, $<10^{-10}$ atmospheres). If we take the surface energy and contact angle of mercury on alumina to be $486 \mathrm{~mJ} / \mathrm{m}^{2}$ and $141^{\circ}$ respectively, considering the range of variation in measured contact angle for copper on alumina, $\varphi$ is predicted to be in the range of 2.2-2.9. This is in good agreement with the measured value of $\varphi=2.6$. Taking $1333 \mathrm{~mJ} / \mathrm{m}^{2}$ for the surface energy of copper at $1200^{\circ}$, an apparent

TABLE I Surface energies and contact angles of $\mathrm{Hg}$ and $\mathrm{Cu}$ on alumina at $25^{\circ} \mathrm{C}$ and $1200^{\circ} \mathrm{C}$, respectively

\begin{tabular}{llll}
\hline Metal & $\sigma_{\mathrm{LV}}\left(\mathrm{mJ} \cdot \mathrm{m}^{-2}\right)$ & Contact angle, $\theta$ & Ref. \\
\hline $\mathrm{Hg}$ & $450-486$ & & 23 \\
$\mathrm{Hg}$ & 380 & $141,150,155$ & 22 \\
$\mathrm{Cu}$ & $1247-1361$ & & $23,26,27$ \\
$\mathrm{Cu}$ & & $114^{\circ}-170^{\circ}$ & $16,24,25$ \\
\hline
\end{tabular}


contact angle of $137^{\circ}$ for copper on alumina particles can be deduced on the basis of the present experimental data.

\section{Conclusions}

1. The Brooks and Corey semi-empirical model agrees with drainage curves relevant to the infiltration by molten copper or mercury of packed alumina powder preforms.

2. The influence of capillary parameters (wetting angle and fluid surface tension) and of the particle volume fraction seem to be embedded in a scaling factor for pressure $P$. Elementary reasoning together with the data indicate that this scaling factor is proportional to the minimum capillary pressure drop in slug-flow infiltration, $\Delta P_{\gamma}$ of Equation 2.

3. Using usual values for relevant capillary parameters, an effective contact angle of $137^{\circ}$ for copper on alumina particles during infiltration at $1200^{\circ} \mathrm{C}$ in an essentially oxygen-free atmosphere is deduced.

\section{Acknowledgements}

This research was carried out under financial sponsorship by the NEDO International Joint Research Grant Program, Project 01MB7.

\section{References}

1. A. MORTENSEN and I. JIN, Intern. Mater. Rev. 37 (1992) 101.

2. A. MORTENSEN, in "Comprehensive Composite Materials," edited by T. W. Clyne, Series editors: A.Kelly and C. Zweben (Pergamon, Oxford UK, 2000) Vol. 3, p. 521

3. A. MORTENSEN, Mater. Sci. Engng. A 135 (1991) 1

4. A. MORTENSEN and J. A. CORnie, Metallurg. Trans. A 18 (1987) 1160

5. C. GARCIA-CORDOVILLA, E. LOUIS and J. NARCISO, Acta Matrialia 47(18) (1999) 4461.

6. N. EUSTATHOPOUlOS, M. G. NICHOLAS and B. DREVET, "Wettability at High Temperatures" (Elsevier, Kidlington, 1999) p. 7,149 and 223.
7. N. R. MORROW, Industr. Engng. Chem. 62(6) (1970) 32.

8. V. MICHAUD and A. MORTENSEN, Composites: Part A 32 (2001) 981.

9. F. DElannay, L. FROYEn and A. DERUyttere, $J$. Mater. Sci. 22 (1987) 1.

10. A. MORTENSEN and T. WONG, Metallurg. Trans. A 21 (1990) 2257.

11. J. BEA R, "Dynamics of Fluids in Porous Media" (American Elsevier, New York, 1972) p. 439.

12. H. KAUFMAN and A. MORTENSEN, Metallurg. Trans. A 23 (1992) 2071.

13. V. J. MICHAUD, L. M. COMPTON and A. MORTENSEN, Metallurg. Mater. Trans. A 25 (1994) 2145.

14. T. DOPLER, A. MODARESSI and V. MICHAUD, Metallurg. Mater. Trans. B 31 (2000) 225.

15. W. ZHANG, J. R. SMITH and A. G. EVANS, Acta Materialia $\mathbf{5 0}$ (2002) 3803.

16. M. DIEMER, A. NEUBRAND, K. P. TRUMBLE and J. RÖDEL, J. Amer. Ceram. Soc. 82 (1999) 2825.

17. M. DAY, I. B. PARKER, J. BELL, M. THOMAS, R. FLETCHER and J. DUFFIE, in "Caracterization of Porous Solids II," edited by F. Rodriguez-Reinoso, J. Rouquerol, K. S. W. Sing and K. K. Unger (Elsevier, New York, 1991) p. 75.

18. H. GIESCHE, "Handbook of Porous Solids" (WILEY-VCH Verlage GmbH, Weinheim, 2002) Vol. 1, p. 309.

19. M. SAHIMI, Rev. Modern Phys. 65(4) (1993) 1393.

20. N. MARTYS, M. CIEPLAK and M. O. ROBBINS, Phys. Rev. Lett. 66(8) (1991) 1058.

21. R. H. BROOKS and A. T. COREY, Hydrology Papers, Colorado State University (1964) No. 3.

22. V. DE JONGHE, D. CHATAIN, I. RIVOLlet and N. EUST A THOPOLOS, Journal de chimie physique 87 (1990) 1623.

23. B. J. KEENE, Intern. Mater. Rev. 38(4) (1993) 157.

24. N. A. TRAVITZKY and A. Shla YEN, Mater. Sci. Engng. A 244 (1998) 154

25. JU. V. NAIDICH, in "Progress in Surface and Membrane Science," edited by D. A. Cadenhead and J. F. Danielli (Academic Press, New York, 1981) vol. 14, p. 386.

26. K. NOGI, K. OISHI and K. OGINO, Mater. Trans. JIM 30(2) (1989) 137.

27. B. C. ALLEN and W. D. KINGERY, Trans. Metall. Soc. AIME 215 (1959) 30.

Received 31 March

and accepted 18 July 2004 